\section{Tatjana Đurišić-Bečanović Univerzitet Crne Gore u Podgorici \\ alextatjana@t-com.me}

Data przesłania tekstu do redakcji: 10.11.2014

Data przyjęcia tekstu do druku: 05.02.2015

\title{
Razgrađivanje emotivnog diskursa u romanu Gullo Gullo Miodraga Bulatovića
}

\begin{abstract}
Bečanović Tatjana, Razgrađivanje emotivnog diskursa u romanu Gullo Gullo Miodraga Bulatovića (Deconstruction of Emotional Discourse in the Novel Gullo Gullo by Miodrag Bulatović). "Poznańskie Studia Slawistyczne" 9. Poznań 2015. Publishing House of the Poznań Society for the Advancement of the Arts and Sciences, pp. 425-437. ISSN 2084-3011.
\end{abstract}

The paper deals with a detailed analysis of the characteristics of emotional discourse, organized in a literary text, specifically in the novel Gullo Gullo by Miodrag Bulatovic. Since expressing of emotions can be verbal and non-verbal, both codes relating the organization of emotional discourse have been activated. In the analysis of literary coded emotional discourse the author had to consider two-instance system of art. The fiction as a basic distinctive feature of a literary text has a crucial influence on the emotional semiosis resulting in producing emotional meaning. That process has always been influenced by various features of poetic language and its combinatorics, which are significantly different from encoding in real chronotope expressed in native language forms, governed by quite different rules of expressing emotions and transferred by the people and not the literary structure.

Since the fact that disorders of phatic function of a language, communication and culture, are defined as major agents of the process in question their accepted values novels written by Miodrag Bulatovic, the author points out the importance of carnival, grotesque, pornography and satire which have been used as the main degradation processes of the canonized cultural and communication patterns in the novel, whose destructive operation inevitably affects the emotional discourse.

KeYwords: emotional discourse; primary emotions; the index character; subversive strategies; grotesque; nonverbal codes; pornography; syntactic figures

U književno kodiranom emotivnom diskursu na ulančavanje verbalnih jedinica presudno utiče afektivno načelo lirizovanog naratora i personalnih medija, pod čijim se emotivnim egzaltacijama artikuliše subjektivno obojena naracija. Iskazivanje emocija može biti i verbalno i neverbalno, pa su u organizaciji emocionalnog diskursa aktivirana oba koda, ali u analizi 
književno kodiranog emocionalnog diskursa moramo imati u vidu i drugostepenost umetničkih sistema. Naime, fiktivnost kao osnovno distinktivno svojstvo književnog teksta presudno utiče na emocionalnu semiozu, to jest proizvođenje emocionalnog značenja. Na taj proces deluju i osobenosti pesničkog jezika i njegove kombinatorike, koja se bitno razlikuje od prirodnojezičkog kodiranja u realnom hronotopu, gde važe drugačija pravila iskazivanja emocija, čiji su nosioci ljudi, a ne književne konstrukcije.

Egzaltirana emocija kao semantička jedinica psihološke tačke gledišta u književnom tekstu mora dobiti odgovarajuću jezičku artikulaciju i manifestovati se na planu frazeologije, što dovodi do modifikacije rečenične strukture, koja se pod uticajem sintaktičkih figura zasnovanih na poremećaju hijerarhije kreće ka paradigmi indeksnog znaka. Uz to se javlja i dominacija patetičnog stila, koji predstavlja adekvatan frazeološki obrazac za iskazivanje hipertrofirane emocije i afektivnih psihičkih stanja likova. Stoga se kao stilske dominante emotivnog diskursa javljaju: ponavljanje, princip paratakse, kumulacija izražajnih sredstava, usklična intonacija i povišen ton, indeksni znak, anakolut, hiperbaton, inverzija i sl. U sintaktičkoj strukturi emotivnog diskursa slabi princip hipotakse, što dovodi do razaranja rečenične periode i destabilizacije odnosa subordiniranosti i superordiniranosti, pri čemu se aktiviraju poetski fenomeni i obeležja poput metriziranja, eufoničnog ulančavanja i stilogenog ponavljanja leksema, rečenica i odeljaka teksta. Na taj način princip analogije i naporednog nizanja, inače dominantan u poeziji, postaje preovladavajući u Bulatovićevoj naraciji. Pri tom mnogobrojne postpozicije, odnosno grananje rečenice na desno i upotreba interpunkcijskih znakova sa primarno ritmičkom funkcijom, proizvode poetsku intonaciju i ritmičku strukturu, što pojačava sugestivno dejstvo rečenice koja prevazilazi svoju sopstvenu informativnu sadržinu i, zahvaljujući svojim prozodijskim faktorima, postaje nosilac dopunskog značenja koje često, uz mimetičku, aktivira i iracionalnu, transcedentnu stvarnost. Defektne strukture, atomizacija, ritmizacija i pojačana emocionalnost iskaza markiraju i frazeologiju ekstradijegetičkog naratora, koja se od objektivne i distancirane transformiše u subjektivnu i poetizovanu, naglašeno lirsku naraciju. Sve opisane stilske osobenosti upućuju na izuzetnu strukturalnu bliskost Bulatovićeve prozne rečenice sa poezijom i njenim konstruktivnim principima, što svedoči o artikulaciji emocionalnog diskursa, koji ugrožava narativno kodiranje teksta 
pretvarajući roman u genološki hibrid. Redukovanje rečenice i broja leksema, kao i narušavanje principa razvijene i logički zasnovane hipotakse korespondira s modelativnim principima narativne zbilje, koji ukidaju logiku i racionalno načelo empirijske stvarnosti, a uvode iracionalno načelo i nadrealne relacije kao paradigmu nove, fantastične stvarnosti.

Dakle, emotivni diskurs u književnom tekstu ne može se izučavati kao u vanknjiževnom kontekstu, jer se osobenosti književne semioze odražavaju kako na organizaciju, tako i na delovanje emotivnog diskursa definišući njegovu ekspresivnu i apelativnu funkciju:

U tome je razlika između racionalnog i afektivnog saznanja: misao o smrti može nas ostaviti ravnodušnim, ali doživljaj smrti nas uvijek potresa. A književnost, na ovaj ili onaj način, predstavlja komunikaciju te druge vrste saznanja. Ona maksimalno ispoljava afektivnu stranu ljudskog bića, jer maksimalno iskorišćava medij u kojem čovjek otkriva - i obnavlja to otkriće - sebe kao čovjeka. Međutim, afektivni naboji riječi u književnoumjetničkom tekstu u nečemu se iz osnove razlikuju od afektivnosti koja prožima živu riječ: emocije koje do izražaja dovode riječi u pjesmi nisu iste vrste kao emocije koje prate živu riječ (Lešić 2008: 210).

Artikulacija emocionalnog diskursa podrazumeva približavanje likova, dakle, invarijantnih jedinica narativnog koda, strukturi lirskog subjekta, čija je osnovna funkcija ispovedanje misli, emocija i raspoloženja. U književnom tekstu emocija se stilizuje i podređuje organizacionim principima književne strukture i njenoj logici, kao i osnovnom načelu fiktivnosti, što dovodi do uspostavljanja veoma složenog komunikativnog sistema, posebno na planu enkodiranja i dekodiranja emocionalne informacije. Naime, tom prilikom formira se dvoplanska komunikativna struktura: jedna unutartekstovna, koja se tiče razmene informacija među likovima, a druga vantekstovna, koja podrazumeva komunikaciju sa čitaocem, gde se otvara novi aspekt delovanja i recepcije emotivnog diskursa. Pri tom je reagovanje likova, to jest književnih konstrukata, na emotivni diskurs podređeno imanentnoj logici književnog teksta, tako da su njihove emotivne reakcije usklađene sa motivacionim i aksiološkim sistemom. Raspored i interferencija psiholoških tačaka gledišta presudna je za organizaciju emotivnog diskursa u književnom tekstu, pa tamo gde dolazi do njene dominacije nad frazeološkom i ideološkom, pri čemu se vrednovanje podređuje emocijama, afektivno načelo uslovljava selekciju verbalnih jedinica, kao i njihovo kombinovanje, što rezultira poremećajima sintaktičkog poretka. Po nekim 
semiotičarima, pojedine verbalne jedinice same po sebi su nosioci emotivnog, to jest evokativnog naboja:

reči su, dakle, u stanju da vrše dubinski uticaj, sasvim neovisno od sudelovanja u tome nekakvih naročitih strasti, potreba, želja, ili okolnosti kod slušaoca. I kao da nema granica mogućnom evokativnom domašaju reči, kako se to, uostalom, u prošlosti već toliko puta bilo pokazalo (Ogden, Ričards 2001: 205).

Dakle, po mišljenju Čarlsa K. Ogdena i Ivora A. Ričardsa, bez obzira na namere govornika, u samim rečima je sadržan određeni emotivni potencijal delovanja, što posebno važi za reči subjektivne ocene, jer sistem vrednovanja, to jest određeni aksiološki parametri u narativnim strukturama, nameću i odgovarajuću selekciju verbalnih jedinica. Kada je u pitanju frazeologija i njeno učešće u artikulaciji emocionalnog diskursa u romanu Gullo Gullo, onda svakako treba skrenuti pažnju na stilski valentnu upotrebu reči subjektivne ocene, od kojih dominiraju psovke, pejorativi, uvrede i ostali oblici verbalnog nasilja, što nesumnjivo pojačava emocionalnost diskursa, kao i izobličenost narativne stvarnosti. Međutim, iako se radi o elementima mikrostrukture, reči subjektivne ocene u ovom slučaju postaju nosioci dopunskih funkcija, pa ukazuju i na neka bitna makrostrukturna svojstva, prvenstveno na groteskni kodni sistem koji preuređuje kompletan tekst pa, između ostalog, utiče na selekciju verbalnih jedinica i deluje kao osnovna razgrađivačka strategija emocionalnog diskursa.

Do afektivnog preobražaja značenja dolazi kako pod uticajem ose selekcije, tako i principa kombinatorike, pa organizacija emotivnog diskursa podrazumeva selekciju emotivno obeleženih verbalnih jedinica, kao i stilska sredstva preterivanja, koja treba da sugerišu lični stav i egzaltiranost govorne instance. To znači da je modalnost, to jest iskazivanje voljnih značenja i ličnog stava, invarijantna jedinica emocionalnog kodiranja diskursa, pri čemu govorna instanca nužno poprima funkcije lirskog subjekta, što dovodi do lirizacije narativnog ili dramskog teksta. Principi kombinatorike u emocionalnom kodiranju manifestuju se u različitim poremećajima sintakse. Naime, nepravilnosti u artikulaciji iskaza ukazuju na afektivno stanje govorne instance, što dovodi do maksimalne emocionalne angažovanosti reči u tekstu, pri čemu inverzija, anakolut i hiperbaton postaju sintaktički signali emotivnog diskursa, koji nastaje unošenjem devijacija $\mathrm{u}$ iskaz, odnosno odstupanjem od norme, jer direktna posledica afektivne 
situacije jeste nastanak deformisanih, nepravilnih iskaza. Međutim, emotivni diskurs se u Bulatovićevoj naraciji podvragava delovanju čitavog niza subverzivnih strategija koje dodatno deformišu njegovo ustrojstvo i značenja. Pošto su poremećaji fatičke funkcije jezika, komunikacije i kulture glavni nosioci procesa desemantizacije u romanima Miodraga Bulatovića, karnevalizacija, groteska i satira koriste se kao osnovni postupci razgrađivanja kanonizovanih kulturnih i komunikacionih obrazaca, čije razorno delovanje zahvata i emocionalni diskurs.

Dakle, sredstva kojima se modifikuje i podešava emocionalni diskurs u romanu Gullo Gullo po tipu su subverzivna, što dovodi do intenzivne razgradnje književno kodirane emocionalnosti, neraskidivo povezane sa ideologijom. Dezintegracijska, razgrađivačka energija romantičarskih kodova i njihova sklonost ka razaranju kanona došla je do punog izražaja u Bulatovićevom narativnom postupku, zasnovanom na maksimalističkim postulatima koji podrazumevaju uništavanje postojećeg sveta, odnosno agresivan odnos prema stvarnosti, što je praćeno aktiviranjem i istovremenim razgrađivanjem emocionalnog diskursa. Na tim subverzivnim strategijama građen je dijegetički univerzum Miodraga Bulatovića, čija destruktivna energija svoj vrhunac dostiže u njegovom poslednjem romanu Gullo Gullo i eshatološkim mitemama. Postupak hiperbolizacije, inače tipičan za romantičarske kodove i egzaltirani, emotivni diskurs, podrazumeva i opsesivnost književnih junaka, koji su po pravilu egzaltirani, preterano emocionalni, izloženi mističkim doživljajima i napregnutim duševnim stanjima: ljubavi ili mržnje, empatije ili zlobe, što dovodi do modelovanja abnormalnih ili natprosečnih, incidentnih likova. Stoga je njihov frazeološki idiom po pravilu organizovan na principu indeksnog znaka, odnosno naglašeno emocionalnog diskursa. Bulatovićev dijegezis naseljen je likovima koji su dovedeni do ludila i izopačenosti, pri čemu je incidentnost u ponašanju njihovo osnovno svojstvo, često zasnovano na iracionalnoj motivaciji. Na taj način likovi se modeluju kao nosioci visokog emotivnog naboja, koji reguliše organizaciju njihovog diskursa, usmeravajući ga ka indeksnom, ekspresivnom znaku, složene emocionalne strukture. Emotivnoj egzaltiranosti junaka doprinosi i patetični stil na kome se gradi njihov frazeološki idiom, što pojačava apologiju bezumlja i aktivira antiracionalističko načelo ekstremnih emocija, koje se zatim podvrgavaju razornom delovanju razgrađivačkih, subverzivnih narativnih i stilskih strategija. Dakle, 
u prikazanom svetu sve je u duhu romantičarske tradicije i emocionalnog diskursa dovedeno do krajnosti, do ekstrema, što se posebno manifestuje u hiperbolizaciji osećanja i uklapa u eruptivni postupak izgradnje sistema krajnosti, pa u Bulatovićevom romanu nema stabilnih semantičkih niti aksioloških struktura.

Proces psihološke destabilizacije lika projektuje se i na organizaciju govornog niza, odnosno frazeološke tačke gledišta, pri čemu dolazi do rasparčavanja rečenične strukture i njene hijerarhije, što podrazumeva i aktiviranje sintaktičkog sistema stilske figuracije. Naime, sintaktičko-semantičke celine u emocionalnom diskursu podležu posebnom tipu uređenja koji se zasniva na principu intonacionog i semantičkog osamostaljivanja rečeničnih delova ili pak poremećaja sintaktičkog poretka, što dovodi do emitovanja pojačane indeksne, odnosno ekspresivne informacije. Intonaciono izolovanje pojedinih subordiniranih elemenata rečenice vodi ka usitnjavanju rečenične strukture i semantičkom osamostaljivanju nesamostalnih delova, to jest ka usložnjavanju njihovih funkcija i značenja, što se postiže pomoću prozodijskih faktora: intonacione zaokruženosti, ubrzanog ritma i odsečnog, pojačanog tempa. Na taj način koloni i artikulusi, po definiciji podređeni članovi sintaktičke strukture, teže da na sebe preuzmu pojedine funkcije i obeležja rečenice, a njihovo odsečno nizanje ubrzava rečenični tempo, dinamizuje i dodatno stilizuje iskaz, koji se organizuje na principu indeksnog, ekspresivnog znaka, ilustrujući potpuno nervno rastrojstvo lika i njegovu emotivnu egzaltiranost.

Međutim, u romanu Gullo Gullo emotivne egzaltacije prelivaju se u ideološke, jer je ovde emocionalnost neraskidivo povezana sa ideologijom, koja postaje dominanta narativne strukture i deformiše sve njene slojeve, pri čemu dolazi do potpune ideologizacije predočene zbilje, pa sve predmetnosti, čak i najbanalnije - telesne, dobijaju ideološki predznak:

Tek posle trećeg rendgenskog snimka ustanovljena je asimetrija lobanje; njena desna površina ima veću zapreminu od leve. Plagiocephalia! (...) Detaljnim ispitivanjem konstatovali smo da kod dotičnog Nossacka postoji status inversus: aorta izlazi iz desne komore, a plućne arterije iz leve. (...) Jednom rečju, kod Kurta Boda Nossacka, svi su organi u krajnje dextra poziciji (Bulatović 1983: 105, 111).

Tim procesom sveopšte ideologizacije zahvaćeni su i elementi diskursa, pa dolazi do ,ideološki” motivisanog eliminisanja interpunkcije: 
„Gullo Gullo, te dve reči najstrožije je zabranjeno okivati znacima navoda, ili podvrgavati bilo kakvoj buržoaskoj ili proleterskoj interpunkciji" (Bulatović 1983: 44). Levičarsko, pobunjeničko uvođenje ,buržoaske interpunkcije" u minus-postupak predstavlja svojevrsno razgrađivanje kako ideološkog, tako i emotivnog diskursa, jer signalizira, između ostalog, i urušavanje sintaktičke hijerarhije. Na taj način sugeriše se urušavanje svakog, pa i društvenog poretka i nagoveštava uništenje sveta do koga će doći na kraju romana. Apokaliptični kraj romana organizuje se kao negacija početnih desničarskih, buržoaskih i konzumentskih kodova, kao i negativnog vrednovanja kune Gullo Gullo. Naime, glavni junak Kurt Bodo Nossack, sa naglašene desne pozicije, prilikom otmice koja će ga dislocirati iz klasifikacionog semantičkog polja (o klasifikacionom semantičkom polju cf. Lotman 1976), izriče vrednosne stavove o levičarskim ideologijama i terorističkom idolu - kuni Gullo Gullo.

Međutim, i desničarski, početni i levičarski, epiloški diskurs Kurta Boda Nossacka organizuju se kao naglašeno emotivni diskurs, jer je u romanu glavni izvor egzaltacija upravo ideologija, tako da se u romanu gradi neka vrsta osobenog ideološkog afekta, čiji su signali: povišena intonacija, ubrzan ritam, sintaktičke anomalije, praćene nekontrolisanim izlivima besa, mržnje i agresivnosti, što dovodi do aktiviranja isključivo disensnih komunikativnih strategija, na kojima se zasniva egzaltirani diskurs hipertrofiranog dijegetičkog univerzuma preplavljenog nasiljem.

Za čoveka kao socijalno biće najvažniji način prenošenja informacije svakako je verbalna komunikacija, a moć izgovorene reči, gotovo pesnički, opisuje čuveni ruski teoretičar književnosti Mihail Bahtin: „Reč je most izgrađen između mene i drugog. Ako se on jednim krajem oslanja na mene, onda se drugim krajem oslanja na sabesednika. Reč je zajednička teritorija između govornika i sagovornika" (Milosavljević 1997: 177). Međutim, ,zajednička teritorija" u naraciji Miodraga Bulatovića izložena je pogubnom delovanju subverzivnih mehanizama, što dovodi do razaranja ustaljenih komunikativnih modela. Naime, u njegovoj naraciji uopšte, kao i romanu Gullo Gullo, učtivost kao strateška manipulacija jezika i način za lakše postizanje konverzacijskih ciljeva potpuno je ukinuta, uvedena u minus-postupak, a verbalno opštenje likova je vulgarizovano i usklađeno s agresivnim parodijskim i karnevalskim, odnosno „terorističkim” organizacionim principima makrostrukture. 
Strategija jezičke interakcije predstavlja veoma značajan element svake komunikacije jer govornici, u zavisnosti od interakcijskog cilja, biraju određene govorne činove koji će im pomoći da taj cilj ostvare. Pri tom se ima u vidu ilokucijska moć pojedinih činova, odnosno perlokucijski efekat koji oni mogu imati na sagovornika a time i na realizaciju cilja, tako da jezička, komunikacijska strategija može biti usmerena na konsens (kooperativnost) ili disens (nekooperativnost) (Ivanetić 1995: 74). Stoga, u izrazito konsensne činove spadaju: izvinjenje, opravdanje, samokritika, prihvatanje, dok su disensni činovi protivkritika, poricanje, pretnja, ismejavanje, ruganje, vređanje. U Bulatovićevom romanu Gullo Gullo komunikacija je u potpunosti usmerena na disensne činove, pri čemu dominantnu ilokucijsku snagu imaju pretnje, upozorenja, psovke, kletve i ostali oblici verbalnog nasilja, ali se ta agresivna jezička energija prenosi i neverbalnim kodovima, odnosno paralingvističkim i ekstralingvističkim sistemima znakova. Dakle, autor organizuje komunikacioni model oslanjajući se gotovo isključivo na destruktivnu ilokucijsku i performativnu snagu i energiju govornog čina, pri čemu disensnu intonaciju pojačava selekcijom ,ideološki” odgovarajućih, agresivnih verbalnih jedinica (vulgarizmi, pejorativi, psovke, uvrede) koje, iako su elementi mikroceline, dobijaju izuzetno semantičko opterećenje pa odražavaju osnovna, destruktivna svojstva i načela makrostrukture, to jest prikazanog sveta u celini. Osnovna, primarna emocija, koja reguliše ponašanje likova i usmerava ih ka disensnim komunikativnim strategijama jeste „potmuo i dubok politički bes” (Bulatović 1983: 7). Bes (gnev) spada u primarne emocije, zajedno sa stahom, ljubavi i mržnjom (cf. Rot 1987), pa Bulatović na sintagmatskoj ravni romana Gullo Gullo kombinuje sve primarne emocije gradeći uzavreli zoopolitički, ideološki i teroristički univerzum.

$\mathrm{U}$ toku antropometrije, inače omiljene fašističke metode, koju izvodi doktor Zola nad telesinom Kurta Boda Nossaka, biće kreiran groteskno izobličen egzemplarni model desno orijentisanog biznismena, kapitaliste zakržljale emocionalne aktivnosti: „Emocionalni centri zakržljali i nalaze se na donjoj površini potiljačnog režnja ili, rečeno našim doktorskim terminom na donjoj površini lobusa occipitalisa" (Bulatović 1983: 105). Sižejna dinamika pak usmeriće ovog junaka ka levičarskoj ideologiji i pojačanoj emocionalnosti, što će predstavljati negaciju početnih kodova, ideoloških, psiholoških i frazeoloških. Emocionalna zakržljalost u romanu Gullo Gullo semiotizuje se kao posledica klasne i ideološke pripadnosti 
desnom i buržoaskom principu, dok je pojačana emocionalnost osobina revolucionarnog, terorističkog, pobunjeničkog diskursa.

„Budući da biće neke ličnosti možemo da tumačimo kao individualni skup socijalno važnih kodova" (Lotman 2004: 31), u romanu Gullo Gullo doći će do ideološkog i psihološkog preinačenja glavnog junaka, jer će sa početnih desničarskih, on preći na ideološki i emotivno sasvim suprotne - levičarske kodove. Dakle, Kurt Bodo Nossack će preinačiti svoje biće pod uticajem nasilne komunikacije sa terorističkom grupom Gullo Gullo, koja se odvija na kanalu Ja - Oni (Lotman 2004), uz naglašeno disensne i agresivne komunikativne strategije. Kao najjači sižejni udar na stabilnost glavnog junaka, koji menja kontekstnu situaciju i izmešta Kurta Boda Nossacka iz desničarskog, kapitalističkog u levičarski, gerilski kontekst, dovodeći do preinačenja njegovog bića, javlja se motiv otmice i boravak u brlogu Gullo Gullo. Taj incident će bitno poremetiti emotivnu i ideološku stabilnost njegovog lika i modifikovati aksiološke parametre, što će ga preusmeriti ka potpunom poništavanju početnog, desničarskog skupa kodova i uspostavljanju novog, drastično pomerenog, pri čemu će junak pokazati visok stepen rasejavanja u ponašanju: „Kurt Bodo Nossak je mirno plakao. Podsećao je na čoveka koji je priznavao psihologiju, poznavao osećanja, voleo nemoguće" (Bulatović 1983: 171).

Psihološka tačka gledišta likova bitno utiče na konstituisanje narativne zbilje, a pošto je uslovljena romantičarskim senzibilitetom, njihovo psihičko stanje je nestabilno, afektivno i prenapregnuto, što rezultira iskrivljenom i deformisanom slikom stvarnosti u kojoj se uspostavljaju hipertrofirane relacije. Introspektivno modelovanje likova u Bulatovićevim romanima realizuje se kroz subjektivno obojenu naraciju ubrzanog ritma sa izrazito metaforičkim značenjima, kao i kroz iskaze opterećene privatnom simbolikom. Pri tom se modeluju ekscentrični i skandalozni oblici oksimoronske van-životne egzistencije nedovršenih i deformisanih ljudi, čije je osnovno svojstvo egzaltiranost i abnormalnost, koji se izražavaju adekvatnim frazeološkim sredstvom - emocionlanim diskursom.

Glavni nosilac i emitent emocionalnog diskursa u romanu Kurt Bodo Nossack negira emocionalnost, što predstavlja samo još jednu subverzivnu strategiju u nizu. Dakle, emocionalni diskurs se stalno uspostavlja, sa jasnim stilskim indikatorima, ali se istovremeno, pod uticajem moćnih subverzivnih strategija, podvrgava razgrađivanju, tako da $u$ tom fluktualnom 
nastajanju, odnosno nestajanju, on u romanu deluje kao jedan od najdinamičnijih mehanizama semiotizacije.

U romanu Gullo Gullo koriste se tehnike i postupci koji deluju na principu hiperbole, to jest preteranosti i neumerenosti svake vrste, poput karikature i grotesknog realizma, koji učestvuju i u organizaciji emotivnog diskursa. Groteskni realizam je pojam Mihaila Bahtina (1967) koji označava specifičan tip slikovnosti zasnovan na preuveličavanju ili hiperboli, čija osobena kombinatorika spaja realno i groteskno viđenje sveta. Manifestuje se u slikama telesnog i fiziološkog, odnosno predstavama ljudskog tela i njegovih funkcija: jedenja, pijenja, pražnjenja, polnog opštenja, koji su prenaglašeni ili stvoreni od spoja suprotnosti (cf. Popović 2007). Osnovna funkcija grotesknog realizma jeste svođenje svega duhovnog, idealnog i apstraktnog na telesno, materijalno i ovozemaljsko, što se poklapa sa desemantizujućim funkcijama ključnog simbola, položenog u same temelje romana - zmije, kao i procesa demitologizacije i desakralizacije, kojima Bulatović razara simbole i čokoladnu civilizaciju u romanu Gullo Gullo. Karikatura takođe deluje na principu hiperbole i hipertrofije, jer izdvajanjem neke karakteristične, spoljašnje ili unutrašnje crte predmeta i njenim namernim preuveličavanjem proizvodi efekte komičnog ili pak grotesknog. Specifičnost karikature je u promišljenom, stilizovanom pojednostavljivanju i preuveličavanju delova predstavljenog objekta, pri čemu estetski efekat proizlazi iz namerne disharmonije elemenata koji tvore iskrivljenu, deformisanu celinu. Smeli, ekstravagantni potezi i preuveličavanje nekih markantnih obeležja ličnosti koju prikazuje omogućavaju karikaturi da funkcioniše kao loša imitacija nekog ozbiljnog posla, uzvišene akcije, egzemplarnog modela ili pak neke ideje. Njena svrha je da tim isticanjem i preuveličavanjem slabosti, poroka i negativnosti u pojedincu, društvu i vremenu, kritički i rastrežnjujući deluje pozitivno i progresivno, kao protest i pobuna protiv kanona i autoriteta. Stoga karikatura funkcioniše kao snažno političko, borbeno i propagandno sredstvo, kao negativ koji ističe sve tamne crte objekta i fiksira drastičnu preteranost, rugobu, nakaradnost i izvitoperenost (cf. Popović 2007). Dakle, i groteskni realizam i karikatura imaju dalekosežnu ideološku funkciju, jer se karnevalsko snižavanje uzvišenog i ozbiljnog tumači kao oblik antidogmatskog slavljenja života - snižavanje kopa grob telu radi novog rađanja, pri čemu se smeh i poruga javljaju kao izraz slobodne i kritičke spoznaje epohe. 
Upravo takve tehnike i modelativne procedure što razaraju uzvišenost, unižavaju i ismejavaju, koriste se u razgrađivanju emocionalnog diskursa, koji se na taj način u romanu Gullo Gullo podvrgava dvostrukoj devijaciji. Naime, prvostepena devijacija podrazumeva deformacije emotivno neutralnog diskursa, koji se transformiše u emotivni, a zatim se aktiviraju subverzivne strategije, čiji je osnovni cilj razgrađivanje emotivnog diskursa i njegovo karikaturalno izobličavanje. Ta drugostepena devijacija veoma je agresivna a njena razorna desemantizujuća energija dostiže vrhunac u karnevalskm postupku parodia sacra, kojim se razara uzvišenost biblijskog stila i patetika emocionalnog diskursa. Spoj nespojivih procedura, koje jedna drugu poništavaju i proždiru u egzaltiranoj verbalnoj i semantičkoj igri uzavrelog zoopolitičkog haosa, predstavlja oksimoronski destruktivnu stilsku bazu za ispisivanje teksta Nove Biblije.

Za Bulatovićevu naraciju tipično je aktiviranje dramskog, scenskog kodiranja, pri čemu tekst simulira predstavu, a likovi deluju kao glumci, što je u romanu Gullo Gullo dovelo do kinematografskog kodiranja naracije, sa posebno izdvojenim postupkom kadriranja. Na taj način otvara se prostor za artikulaciju upravnog govora likova, to jest diskursa, pri čemu se posebno izgrađuju samostalni frazeološki idiomi, od kojih je većina organizovana na principu emocionalnog diskursa, jer je situacija ekstremna, pred smak sveta, to jest uništenje postojeće, konzumentske civilizacije:

Kurt Bodo Nossak se trudio da bude što razložniji, pa je gotovo svaku reč pomagao pokretima: Život je kratak... vrlo kratak, prijatelji... da bismo ga, na ovoj zapari, provodili napolju... a kad bolje pogledamo, zar ne, da svima otkucava, odbrojava, pa je svejedno hoćeš li odleteti u vazduh danas ili sutra... zato vas pozivamo, kamerat Szabo i ja, da uđete... znate, sa Szabom, mojim predivnim Mađarom, telefonski sam razgovarao nema pun sat, najviše dva, pre polaska ovamo... moj uvek nadahnuti Mađar, moje drugo, moje fizičko ja, izvestio me da će čaj, i sve što uz to ide, za kakvih trideset, pedeset osoba biti postavljen... izvolite, ne bojte se eksploziva, kojeg je puna kuća, to je defanzivno, čak ću reći humano oružje, pravi sedativ... izvolite, ili popularnije rečeno: napred za mnom... nek i moj dom, jednom zauvek, postane proleterskom menzom (Bulatović 1983: 199-200).

Koncentracija egocentričnih reči (ja, moj, ovamo) u navedenom primeru upućuje na pojačanu ekspresivnu funkciju poruke, dok direktno obraćanje i upotreba drugog lica množine pojačava njenu apelativnu funkciju, odnosno perlokucijski efekat, to jest uticaj na recipijenta. Naglašena pak gestikulacija emitenta poruke tipična je upravo za emocionalni, ne za 
„,razložni” diskurs, a na povišen stepen emocionalnosti ukazuju i frazemi imenovanja, koji otkrivaju naglašeno subjektivan stav govornika prema objektu vrednovanja: mojim predivnim Mađarom, moj uvek nadahnuti Mađar... Dakle, narator tvrdi da se radi o „,razložnom” diskursu, međutim, demantuju ga organizaciona načela kako na planu selekcije tako i na planu kombinatorike, koja svedoče o artikulaciji upravo emocionalnog diskursa, oslonjenog na neverbalne kodove, pouzdane prenosioce emocionalne informacije jer Nossack gotovo svaku reč potpomaže pokretima.

„Citatna zver” Gullo Gullo deluje kao eksploziv položen u ranjivo tkivo Istorije i Kulture, kao antimemorijska kartica koja usisava sve slojeve prošlosti do civilizacijskog iskona da bi ispisala metatekst Nove, reformisane Biblije, u kojoj su preuređene arhetipske relacije i parametri, ukinute sve opozicije, a svet vraćen u stanje pre genesisa i božanske intervencije. Dakle, citatnost kao pouzdano sredstvo, to jest svojevrsna memorijska kartica za čuvanje prošlosti, u Bulatovićevom romanu demonski je reprogramirana na principu status inversus i usmerena protiv sebe same, protiv moćne intertekstualne sile koja uspostavlja Kulturu, Tradiciju i Istoriju. Gullo Gullo je „citatna zver” koja putuje kroz vreme i proždire kanonske tekstove u agresivnoj polemici sa Tradicijom, pri čemu se citatna dimenzija romana nameće kao ključ za razumevanje njegove visoko organizovane simboličko-narativne strukture, koja počiva na veoma produktivnim subverzivnim procedurama, što tekstu obezbeđuje veliku količinu entropije i pretvara ga u provokativnu i hermetičnu estetsku poruku:

Da, Gullo Gullo jede, ždere, guta, kad već hoćete tako da se izrazimo, ali on to ne čini samo zato što ga je priroda stvorila kao žderavca. Gullo Gullo jede da ne bi plakao, da se ne bi sećao, s obzirom da je Gullo Gullo jedini živi stvor u čijem je duhu sadržano celokupno pamćenje njegovog roda, a delimično i ljudskog roda. Gullo Gullo, da se razumemo, ne voli svoje pamćenje, svoju očiglednu osećajnost, Gullo Gullo dakle ne priznaje psihologiju. No, Gullo Gullo nikako da se oslobodi memorije... (Slika pokazuje kako Gullo Gullo opkoračuje svoju dugorepu draganu, kako joj ga ugoni, kričeći pri tom, dok sirota izabranica, već u sledećoj sekvenci, iz utrobe i na mećavu, izbacuje tuce, dva, tri tuceta gulića). Gullo Gullo srče krv, loče je naprosto, sve rastrže kandžama, da bi jebao! Gullo Gullo, kad mu je daleko dragana, kad je s drugim životinjama, natakne šta stigne... (Slika donosi moćnu, ljubičastu žilu glavića okrenutog ulevo, te strah ispunjava ekran do poslednjeg milimetra) (Bulatović 1983: 178).

To što Gullo Gullo ne može da se oslobodi memorije znači da se ne može osloboditi ni emocija. Međutim, u duhu svoje razgrađivačke poetike, 
autor modeluje skarednu sliku polnog opštenja kune Gullo Gullo i njegove drage, i na taj način razara emocionalni diskurs pornografskim kodom. Dva glavna nosioca emocionalnog diskursa u romanu Kurt Bodo Nossack i kuna Gullo Gullo uporno negiraju osećanja i psihologiju, a njihovi polni organi ideološki su markirani, pa je kod kune glavić okrenut u levo, kod Nosaka u desno (sve do levičarske evolucije), što predstavlja još jednu subverzivnu strategiju kojom Bulatović razgrađuje kako emocionalni, tako i ideološki diskurs. Dakle, jedna od ključnih razgrađivačkih strategija emocionalnog diskursa u romanu Gullo Gullo jeste pornografski kod, koji najbrutalnije razara samu suštinu emocionalnosti i najšokantnije deluje na recipijenta.

I da zaključimo, sredstva kojima se modifikuje i podešava emocionalni diskurs u romanu Gullo Gullo po tipu su subverzivna, što dovodi do intenzivne razgradnje književno kodirane emocionalnosti, neraskidivo povezane sa ideologijom. Dezintegracijska, razgrađivačka energija satire, groteske, karikature, karnevalizacije i pornografije usmerena je na razaranje emocionalnog diskursa u ovom Bulatovićevom romanu, a na taj način razgrađuju se i ključni elementi dijegezisa - likovi, nosioci i emitenti emocionalnosti. Upravo zahvaljujući tom fluktualnom procesu izgradnje $\mathrm{i}$ istovremenog razgrađivanja emocionalnog diskursa, on deluje kao jedan od najdinamičnijih mehanizama semiotizacije u romanu Gullo Gullo.

\section{Literatura}

Bahtin M., 1967, Problemi poetike Dostojevskog, prev. M. Nikolić, Beograd.

Bulatović M., 1983, Gullo Gullo, Beograd-Zagreb.

Ivanetić N., 1995, Govorni činovi, Zagreb.

Lešić Z., 2008, Teorija književnosti, Beograd.

Lotman J., 1976, Struktura umetničkog teksta, Beograd.

Lotman J., 2004, Semiosfera, Novi Sad.

Milosavljević P., 1997, Teorija književnosti, Beograd.

Ogden Č.K., Ričards A.A., 2001, Značenje značenja, prev. M. Radovanović, Sremski Karlovci-Novi Sad.

Popović T., 2007, Rečnik književnih termina, Beograd.

Chevalier J., Gheerbrant A. (ur.), 2003, Rječnik simbola, prev. A. Buljan, D. Bućan, F. Vučak, M. Vekarić, N. Grujić, Banja Luka.

Rot N., 1987, Opšta psihologija, Beograd.

Trebješanin Ž., 2001, Rečnik psihologije, Beograd. 